\title{
Embedded User Interface for LED Lighting System using LPC2148
}

\author{
Jeetpal Singh \\ ECE Department \\ Lingaya's University \\ Faridabad
}

\author{
S.V.A.V Prasad,Ph.D \\ DEAN \\ Lingaya's University \\ Faridabad
}

\author{
Arvind Pathak \\ Assistant Professor \\ Lingaya's University \\ Faridabad
}

\begin{abstract}
This proposed work is to develop embedded user interface for efficient interior led lighting system which can be used to control LED down light panels, check status form the installed LED panels of interior LED lighting system in the entire building. This will be a hand held device (i.e. operates on a $5 \mathrm{~V}$ DC power with a graphical LCD digital user interface) which can configure lighting arrangements in different places like hospitals, colleges, offices, malls, houses, etc. The only advantage of this controlling device is that it will be a single solution controlling device. This will manage the lighting needs of the entire building.
\end{abstract}

\section{Keywords}

LPC2148, GLCD

\section{INTRODUCTION}

The aim of the project is to develop embedded user interface for efficient interior led lighting system which can be used to check status of LED down light panels and control installed LED panels of interior LED lighting system in the entire building. This will be a hand held device (i.e. operates on a $5 \mathrm{~V}$ DC power with a graphical LCD digital user interface) which can configure lighting arrangements in different places like hospitals, colleges, offices, malls, houses, etc. The advantage of the device is that it will be a single solution controlling device. This will manage the lighting needs of the entire building. This project will also handle all issues required to design packets which has to be transferred to the controlling server from the hand held device. Transmission of packets can be analyzed on serial monitoring software at the receiving end. This is a disadvantage for most general lighting applications, but can be an advantage for spot or flood lighting [9]. Globally, electric lighting accounts for some one fifth of all electric energy consumed [3]. Therefore any efficient electric lighting initiative is a subject of interest of all mankind. Such an initiative is dimming the LEDs in a LED panel [5] [8]. Dimming led saves energy at a roughly 1:1 ratio. This means that if you dim LEDs down to $50 \%$ of their output you will save nearly $50 \%$ of your energy usage [6] [4] [2]. Dimming LEDs run cooler than the existing tube lights and bulbs, which should extend the life of the electronic components of the driver, as well as prosper on the LEDs. Dimming of the light output of White LED down panel is done with pulse width modulation in order to maintain a consistent color or color temperature of light [7]. The hardware platform used in this case is ARM microcontroller. The selected ARM family member for this device is LPC2 148 which is a low power device and can support operations of the complete embedded system with a battery which further improves battery life as it consumes very less power. Provisions will be there to integrate the device with LAN which can be easily done if it is required in future. LPC2148 microcontroller is a 32 bit microcontroller which also has on chip support for USB2.0.

\section{SYSTEM ARCHITECHTURE}

In the system architecture, ARM7 microcontroller is used i.e. LPC2148 member, it is a 32-bit microcontroller. As in the above block diagram, it shows that packet analyzer and switch panel work as an input and GLCD display works as an output. The whole hardware platform is communicating through RS232 with computer or laptop to show the packet data using serial monitoring software.

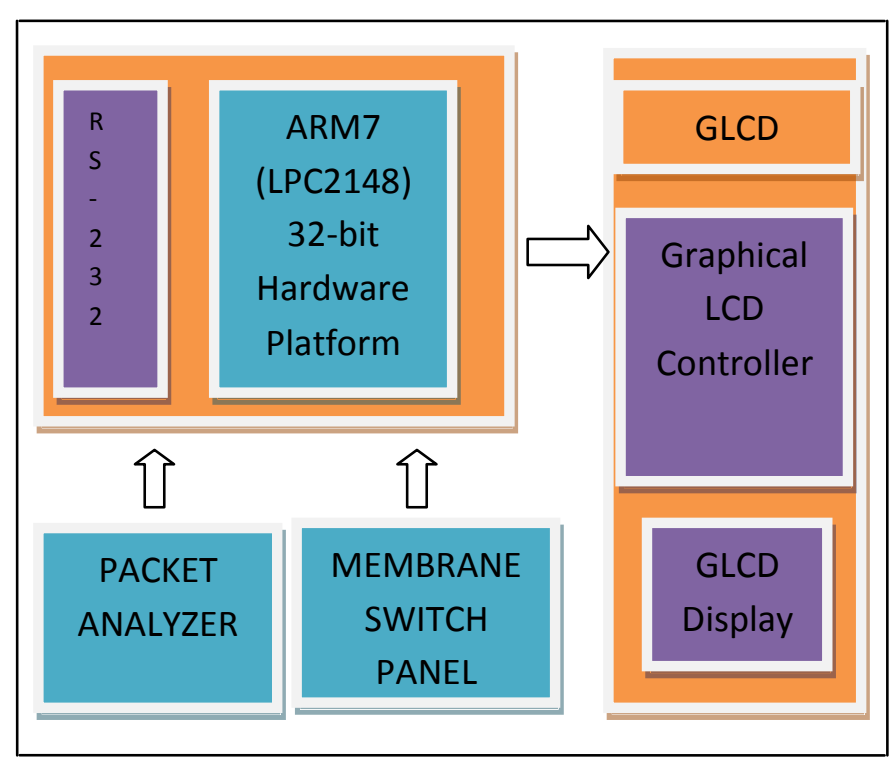

Figure 1: Block Diagram

\section{TRAVERSING AND CONTROLLING PANEL}

In this handheld device, there are total six numbers of switches, which are used to control the operation. Three switches for selecting the floor, room and panel. And other three switches are used to select the number of floor, room and panel. For example in this paper the work done is to 
design the embedded user interface for controlling the led light panels using LPC2148. The command packets are designed for three floor having three rooms in each floor and three light panels in each room of the floor. If there is a need to control light of $3^{\text {rd }}$ floor's room no. 2 and panel no. 1 , for this first press the floor switch and then press the number of floor, then press the room switch and number of room and at last press the panel switch and number of panel.

\section{COMMAND PACKET DESIGN FORMAT}

\begin{tabular}{|l|l|l|l|l|l|l|l|}
\hline FA & FB & RA & RB & PA & PB & OP1 & OP2 \\
\hline
\end{tabular}

\section{Floor Select Bits}

$$
\begin{array}{l|l}
\text { FA } & \text { FB } \\
\hline
\end{array}
$$

Bit location FA and FB are used to select floor in a building. FA is MSB (most significant bit) and FB is LSB (least significant bit). There are four different combination for bit location FA and FB. These are 00, 01, 10 and 11. Combination 00 represents that floor 1 is selected, combination 01 represents that floor 2 is selected, combination 10 represents that floor 3 is selected, combination 11 represents that floor 4 is selected. Following table will give more idea about floor selection.

\begin{tabular}{|c|c|c|}
\hline FA & FB & Description \\
\hline 0 & 0 & Floor 1 \\
\hline 0 & 1 & Floor 2 \\
\hline 1 & 0 & Floor 3 \\
\hline 1 & 1 & Floor 4 \\
\hline
\end{tabular}

Table 1: Floor Select Bit Pattern

\section{Room Select Bits}

\section{\begin{tabular}{l|l|} 
RA & RB \\
\hline
\end{tabular}}

Bit location RA and RB are used to select room in a floor. There are four different combination for bit location RA and RB. These are $00,01,10$ and 11 . Combination 00 represents that room 1 is selected, combination 01 represents that room 2 is selected, combination 10 represents that room 3 is selected, combination 11 represents that room 4 is selected. Following table will give more idea about room selection.

\begin{tabular}{|c|c|c|}
\hline RA & RB & Description \\
\hline 0 & 0 & Room 1 \\
\hline 0 & 1 & Room 2 \\
\hline 1 & 0 & Room 3 \\
\hline 1 & 1 & Room 4 \\
\hline
\end{tabular}

Table 2: Room Select Bit Pattern

\section{Led Panel Select Bits}

$$
\begin{array}{l|l|}
\text { PA } & \text { PB } \\
\hline
\end{array}
$$

Bit location PA and PB are used to select floor in a building. There are four different combination for bit location PA and PB. These are 00, 01, 10 and 11 . Combination 00 represents that panel 1 is selected of specific room and floor, combination 01 represents that panel 2 is selected of specific room and floor, combination 10 represents that panel 3 is selected of specific room and floor, combination 11 represents that panel 4 is selected of specific room and floor. Following table will give more idea about panel selection.

\begin{tabular}{|c|c|c|}
\hline PA & PB & Description \\
\hline 0 & 0 & Panel 1 \\
\hline 0 & 1 & Panel 2 \\
\hline 1 & 0 & Panel 3 \\
\hline 1 & 1 & Panel 4 \\
\hline
\end{tabular}

Table 3: Panel Select Bit Pattern

\section{Operation Select Bit}

$$
\begin{array}{|l|l|}
\hline \text { OP1 } & \text { OP2 } \\
\hline
\end{array}
$$

Finally the bit location OP1 and OP2 is used to operate the panel. They have four different combination for bit location OP1 and OP2. These are 00, 01, 10 and 11. Combination 00 represents that "Light OFF" is selected of specific Panel, room and floor, combination 01 represents that "Light ON" is selected of specific panel, room and floor, combination 10 represents that Intensity of the Light panel reduced to $50 \%$ is selected for specific panel, room and floor, combination 11 represents that Intensity of the Light panel is reduced to $25 \%$ is selected for specific panel, room and floor. The OP stand for Operation code.

Following table will give more idea about panel selection.

\begin{tabular}{|c|c|c|}
\hline OP1 & OP2 & Description \\
\hline 0 & 0 & OFF \\
\hline 0 & 1 & ON \\
\hline 1 & 0 & Intensity $50 \%$ \\
\hline 1 & 1 & Intensity $25 \%$ \\
\hline
\end{tabular}

Table 4: Operation Select Bit Pattern

\section{HERARCHICAL PAGE LAYOUT FORMATION}

In figure 2 , there are three levels in the proposed design. These are three levels i.e. L1, L2 and L3. In level L1, it shows the selection of floor. There are three options for select the floor F1, F2 and F3. The floor is selected by the given switches on the device. In level L2, it shows selection of room from the selected floor. There are three options to select the room R1, R2 and R3. The selection of room is also selected 
by given switches. At last level L3, it shows selection of panel from the selected room and floor. There are three options to select the panel P1, P2 and P3. The selection of panel is also selected by switches.
L1

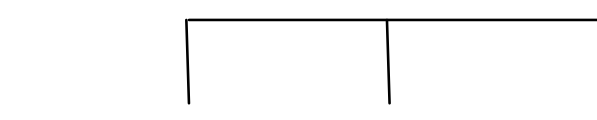

L2

R1

L3 $\overline{\text { P1 P2 P3 }}$
R2

P1 P2 P3
R3

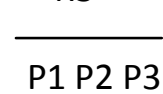

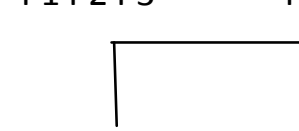

R1

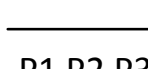

P1 P2 P3
R2

P1 P2 P3
F3

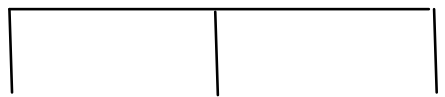

R1

R2

R3

Figure 2: Operation Select Bit Pattern

\section{SYSTEM OPERATIONS}

For this handheld device, the data packets are used to perform the operation which is basically required. There is 8-bit data packet required to do operation. Figure 3, shows an example to perform an operation.

\begin{tabular}{|l|l|l|l|l|l|l|l|}
\hline 1 & 0 & 0 & 0 & 0 & 1 & 0 & 1 \\
\hline
\end{tabular}

Consider the 8- bit data shown in the above byte. Its first 2 bits stand for floor, which is 10 for floor no.3, next 2-bits for room which is 00 for room no.1, next 2-bits for panel which is 01 for panel no. 2 and last 2-bits for operation which is 01 for final operation. The selection of floor, room, panel and operation are explained in the above section titled command packet designing format.

In the following figure the flow of packet data is shown in the form of flow diagram.
L1

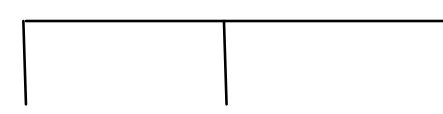

L2

R1

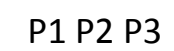

R2

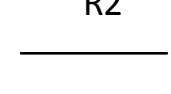

R3

P1 P2 P3

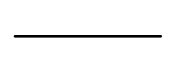

P1 P2 P3

F2

P1 P2 P3

P1 P2 P3

P1 P2 P3

Figure 3: Operation Select Bit Pattern 
The desired selected of operation is F3, R1, P2 and ON

In this example, here operator wants to switch ON the LED panel of selected floor no.3, room no. 1 and panel no. 2 of the selected room of desired floor.

\section{COMPARATIVE STUDY OF EXISTING TECHNIQUES}

The following table gives the comparison between Incandescent bulbs, Fluorescent tube lights, CFL and LED

\begin{tabular}{|c|c|c|c|c|}
\hline & Incandescent & Tube lights & CFL & LED \\
\hline Light intensity & Cannot be controlled & Cannot be controlled & Cannot be controlled & Can be controlled \\
\hline Lifespan & Approx 1200 hours & 8000 hours & 10000 hours & 50000 hours or more \\
\hline Power in Watts & $40 \mathrm{~W}$ & $16 \mathrm{~W}$ & $10 \mathrm{~W}$ & $6 \mathrm{~W}$ \\
\hline Contains Mercury & $\mathrm{No}$ & Yes & Yes & No \\
\hline Produce heat & Yes (higher than others) & Yes & Yes & $\begin{array}{c}\text { Very much lower than } \\
\text { others }\end{array}$ \\
\hline Eco-friendly & $\begin{array}{l}\text { No (affects more on } \\
\text { environment) }\end{array}$ & No & No & Yes \\
\hline RoHS Complaint & Yes & No & No & No \\
\hline Optical Efficiency & Lowest among all & Moderate & Moderate & High \\
\hline $\begin{array}{l}\text { Power Consumption in } \\
\text { a year }[20]\end{array}$ & $2190 \mathrm{KWh}$ approx & $531 \mathrm{KWh}$ approx & $531 \mathrm{KWh}$ approx & $228 \mathrm{KWh}$ approx \\
\hline Cost of Bulbs & $\$ 2$ & $\$ 1.4$ & $\$ 2-\$ 3$ & $\$ 25-\$ 30$ \\
\hline $\begin{array}{l}\text { Annual Operating \& } \\
\text { Maintenance Costs }\end{array}$ & $\begin{array}{l}\text { Money spent is much } \\
\text { higher than others }\end{array}$ & $\begin{array}{l}\text { Less than incandescent } \\
\text { bulbs }\end{array}$ & $\begin{array}{l}\text { Less than incandescent } \\
\text { and slightly higher than } \\
\text { tube lights. }\end{array}$ & $\begin{array}{l}\text { Much lower than the } \\
\text { existing lighting } \\
\text { technology. }\end{array}$ \\
\hline
\end{tabular}

Table 5: Comparison between Incandescent bulbs, Fluorescent tube lights, CFL and LED

\section{RESULTS}

The command packets have been designed and corresponding operation have been performed. The command packets generated to perform a specific task are then analyzed on serial monitoring software and decoding is performed.

\section{CONCLUSIONS}

Finally, this work includes designing of data packets that would control an LED lighting system. Command packets are designed in 8 bit format which will be sent from the handheld device for controlling and analysis applications. These packet formats are analyzed by using serial monitoring software. With the help of command packets handheld device can perform various operations viz. device panel selection from different rooms on different floors in a building and changing intensity of the LED panel. With this design, they have achieved a universal handheld device packet generator which can perform various controlling operations on interior LED lighting system remotely.

\section{ACKNOWLEDGEMENT}

The author would like to thank Mr. Arvind Pathak for the guidance and all the other faculty members for their support. Special thanks for Lingaya's University for their support and also providing labs with all the required equipments.

\section{REFERENCES}

[1] Youjin Kim, Insu Kim, Tae-gyu Kang, Seong-hee Park "Analysis of IP-based Control Networks for LED Lighting Fixture Communication."; New Trends in Information Science and Service Science (NISS);May 2010; 307-312
[11]. From the above table it can be analyses that LED lights are the best when compared with existing lighting technologies. LED light are accepted globally since they do not contain lead or mercury. Emission of UV rays is also not there in case of LED lights. LED lights have highest operational lifespan so it is more suitably opted in energy shortage countries. 